Neutrophilic inflammation in childhood asthma

\section{Neutrophil airway inflammation in childhood asthma}

\section{M McDougall, P J Helms}

\section{A novel and inviting therapeutic target?}

A though asthma has its highest prevalence in childhood, it is generally less severe than in adolescents and adults. ${ }^{1}$ Whether the high population prevalence is because symptoms are more noticed by parents or whether the more physically active lifestyle and natural inquisitiveness of children, particularly young children, unmasks bronchial hyperresponsiveness and related symptoms remains elusive to investigation. Whatever the explanation, the population prevalence of asthma and associated symptoms including wheeze and cough remains high, although with recent evidence of stabilisation or even a decline in those countries (including the UK) at the top of national prevalence "league tables". ${ }^{1-4}$

The investigation of underlying mechanisms is challenging in children because of ethical considerations and the limited applicability of invasive procedures such as bronchoscopy, bronchoalveolar lavage (BAL), and bronchial biopsy. In this context, the report by Li et al in the present issue of Thorax $^{5}$ using the sputum induction technique raises a number of important issues and points to lines of investigation and management that merit further development.

\section{COUGH}

As pointed out by Li et al, cough is a well recognised and frequent accompaniment of asthma and wheezing illness, although when an isolated and prominent symptom it is a poor predictor of subsequent wheezing illness and asthma. ${ }^{67}$ Cough can have important habit and psychogenic contributions, appears to be viewed as an important and worrying symptom by parents, ${ }^{8}$ and is poorly responsive to a range of popular and widely available "over the counter" treatments including antihistamines and antitussives, ${ }^{9}$ as well as inhaled corticosteroids. ${ }^{10}$ However, in the context of a confirmed diagnosis of asthma, cough is a well established although imprecisely quantifiable feature, unless assessed objectively by recording devices such as that described by Li et al..$^{5}$ As the majority of symptomatic asthmatic children are also atopic, it is widely assumed that all the accompanying symptoms (including cough) are associated with eosinophilic airway inflammation, a conclusion that appears to have been confirmed in a recent study from the same author, albeit in a more severely affected clinic based population. ${ }^{11}$ However, the major inflammatory cell type observed in induced sputum in Li's present study ${ }^{5}$ in less severely affected children-likely to be more representative of the symptomatic population-was the neutrophil, cell counts of which were positively correlated with objectively recorded cough frequency. The observation that, during acute episodes in asthmatic children with cough as a major symptom, cough receptor sensitivity appears to be independent of the degree of airflow obstruction also suggests different mechanistic pathways. $^{12}$

\section{SAMPLING THE AIRWAY}

The advent of flexible bronchoscopy, bronchial biopsy, BAL, and induced sputum has enabled the assessment of airway inflammation to flourish. In adults the place of $\mathrm{T}$ cell driven eosinophil mediated airway inflammation in many cases of atopic asthma is established, ${ }^{13}$ although it is recognised that not all asthmatic inflammation is eosinophilic. ${ }^{14}$ Indeed, neutrophilic inflammation is found in severe persistent asthma, ${ }^{15}$ asthma exacerbations, ${ }^{16}{ }^{17}$ sudden onset fatal asthma, ${ }^{18}$ occupational asthma, ${ }^{19}$ and nocturnal asthma. ${ }^{20}$ In children the study of airway inflammation is hampered by ethical and practical constraints and consequently many of the reported BAL/biopsy studies are opportunistic, using patients undergoing clinically indicated bronchoscopy. ${ }^{21-23}$ The generalisability of the findings from such studies to the wheezing population as a whole is therefore questionable. However, studies using non-bronchoscopic BAL in intubated children undergoing minor elective surgery for non-respiratory indications $^{24} 25$ and studies based on induced sputum are potentially more representative, although the latter technique is only possible in cooperative children generally above the age of 6-7 years.

\section{AIRWAY INFLAMMATION}

Although it is increasingly recognised that there are many different childhood wheezing phenotypes, studies of airway inflammation in symptomatic children have had differing inclusion criteria and have not always clearly defined the phenotypic characteristics of the participants. Furthermore, all the published studies are cross sectional with no longitudinal studies addressing the relationships between airway inflammation and disease progression. Notwithstanding these limitations, evidence of different patterns of airway inflammation during exacerbations and in the stable state in children-including some very young children ${ }^{21}{ }^{26}$-is emerging. Increased total cell number in BAL fluid and/or induced sputum, ${ }^{21} 26$ increased numbers of epithelial cells implying airway epithelial damage and desquamation, 22 activated alveolar macrophages $^{28}$ and other markers of activated cells and mediator release ${ }^{21} 25$ have all been reported. Several studies have confirmed the presence of eosinophils in atopic asthma, ${ }^{23} 27$ in keeping with findings in atopic asthmatic adults. However, children who wheeze only with viral infections do not have evidence of eosinophilic inflammation but rather inflammation more typically characterised by neutrophilia. ${ }^{22}{ }^{24}$ Some exacerbations of asthma in childhood have been shown to be associated with increased neutrophils in sputum, ${ }^{29} 30$ and now we have evidence of an association between sputum neutrophils and objectively recorded cough frequency in children with mild atopic asthma. ${ }^{5}$

High neutrophil counts may, in part, be due to bacterial and/or viral infection, particularly where samples were obtained in children with persistent treatment resistant symptoms including cough, or in those with persistent chest radiographic changes. In contrast to bronchial biopsies, BAL fluid specimens and sputum contain those cells that have "escaped" from the lung and caution must be exercised in assuming that the same cells will be abundantly present in the lung parenchyma. Furthermore, the numbers and percentages of cells detected by staining in BAL fluid or sputum may not accurately reflect their state of activation or the levels of mediators that they produce. BAL fluid or sputum cell counts may also be affected by patients' medication. Corticosteroids can reduce eosinophil numbers while increasing neutrophil numbers through opposing effects on the rate of granulocyte apoptosis. ${ }^{31} 32$ However, while acknowledging these 
caveats, the possible significance of neutrophilic inflammation in childhood airway diseases cannot be ignored and merits further investigation of the underlying mechanisms and long term implications for disease progression.

\section{MECHANISMS AND CONSEQUENCES}

The presence of airway neutrophilia implies increased neutrophil recruitment, increased neutrophil survival, or both. The pathogenesis of airway neutrophilia is likely to be multifactorial, dependent on a complex interplay of chemokines and lipid mediators from both resident airway cells and infiltrating inflammatory cells, as well as enhanced adhesion molecule expression and neural activity. ${ }^{33}$ The airway epithelium plays a pivotal role in airway inflammatory responses ${ }^{34}$ and is an abundant source of chemokines with potent neutrophil chemoattractant activity, ${ }^{35}{ }^{36}$ the release of which is promoted by a range of stimuli. It has been argued that physical triggers such as viruses, lipopolysaccharides, and ozone may be more important inducers of airway neutrophilia than any primary immunological cause, ${ }^{37}$ and epithelial interleukin (IL)-8 has been implicated as one of the most likely neutrophil chemoattractants in response to these insults. ${ }^{16}{ }^{30}$ Leukotriene B4 (LTB4), primarily a product of macrophages and neutrophils but also released by keratinocytes, lymphocytes and mast cells, has also been shown to contribute significantly to neutrophil chemotactic activity in lung secretions. ${ }^{38}$

Neutrophil apoptosis permits neutrophil recognition and ingestion by macrophages, leading to their clearance from sites of inflammation. Inflammatory mediators including IL$1 \beta$, tumour necrosis factor, granulocytemacrophage colony stimulating factor, granulocyte colony stimulating factor, and interferon $\gamma$, many of which have been implicated in asthma, ${ }^{36}$ have been shown to inhibit neutrophil apoptosis. ${ }^{39}{ }^{40}$ Furthermore, this enhanced neutrophil survival is associated with functional longevity, with the cells retaining the capacity to generate and release toxic products. ${ }^{40}$ Neutrophil apoptosis is suppressed in acute respiratory distress syndrome in adults ${ }^{41}$ and in chronic lung disease of prematurity, ${ }^{42}$ both of which are associated with airway neutrophilia. It is therefore tempting to speculate that the neutrophilic inflammation observed in childhood wheezing and cough may also be associated with impaired neutrophil apoptosis.

It is also important to consider the consequences of neutrophilic inflammation and, with reference to the paper by
Li et al, ${ }^{5}$ how such inflammation might contribute to persistent cough. In this context it is important to establish not only the presence of inflammatory cells in the lungs but also whether they are quiescent or activated. Although the presence of some quiescent neutrophils in the lungs may have no functional consequences, ${ }^{43}$ activated neutrophils could have a role in the pathophysiology of airway disease through their release of reactive oxygen species, cytokines, lipid mediators, and enzymes including elastase, cathepsin G and myeloperoxidases and non-enzymatic defensins. ${ }^{44}$ Neutrophil derived serine proteinases and defensins markedly affect the integrity of the epithelial layer, decrease ciliary beat frequency, and induce the synthesis of epithelium derived mediators that may influence the amplification and resolution of inflammation. ${ }^{45}$ Neutrophil proteases, especially neutrophil elastase, can also activate eosinophils $^{46}$ and are important mucin secretagogues for goblet cells and submucosal gland cells ${ }^{47}$ and, by inference, likely to contribute to mucus hypersecretion. Neutrophil products may also be mediators of increased vascular permeability $^{48}$ and may directly contribute to airway hyperresponsiveness. ${ }^{49}$

Current anti-inflammatory treatments for asthma target inflammation in general or specific inflammatory pathways other than those involved in neutrophil recruitment. Not only do such treatments fail to tackle neutrophilic inflammation, but steroids may actually exacerbate it by enhancing neutrophil survival. ${ }^{31}$

\section{CONCLUSIONS}

The present report by Li et $a l^{5}$ adds to the emerging body of evidence that a significant proportion of asthma and wheezing illness in both adults and children is associated with neutrophilic airway inflammation and that this pattern is not limited to individuals with severe symptoms. This raises important and interesting questions regarding the mechanisms and consequences of neutrophilic inflammation, as well as presenting a novel and inviting therapeutic target.

Thorax 2006;61:739-741.

doi: $10.1136 /$ thx.2005.057984

\section{Authors' affiliations}

C M McDougall, P J Helms, Department of Child Health, University of Aberdeen, Royal Aberdeen Children's Hospital, Aberdeen AB25 2ZG, UK

Correspondence to: Professor P J Helms, Department of Child Health, University of Aberdeen, Royal Aberdeen Children's Hospital,
Aberdeen AB25 2ZG, UK; p.j.helms@abdn.ac. uk

Funding: $C M C D$ is supported by an MRC Clinical Research Training Fellowship

Competing interests: none declared.

\section{REFERENCES}

1 Anderson HR, Ruggles R, Strachan DP, et al. Trends in prevalence of symptoms of asthma, hay fever, and eczema in 12-14 year olds in the British Isles, 1995-2002: questionnaire survey. BMJ 2004;328:1052-3.

2 Toelle BG, $\mathrm{Ng} \mathrm{K}$, Belousova E, et al. Prevalence of asthma and allergy in schoolchildren in Belmont, Australia: three cross sectional surveys over 20 years. BMJ 2004;328:386-7

3 Braun-Fahrlander C, Gassner M, Grize L, et al. No further increase in asthma, hay fever and atopic sensitisation in adolescents living in Switzerland. Eur Respir J 2004;23:407-13.

4 Gibson PG, Simpson JL, Chalmers AC, et al. Airway eosinophilia is associated with wheeze but is uncommon in children with persistent cough and frequent chest colds. Am J Respir Crit Care Med 2001;164:977-81.

5 Li AM, Tsang TWT, Chan DFY, et al. Cough frequency in children with mild asthma correlates with sputum neutrophil count. Thorax 2006;61:747-50.

6 Brooke AM, Lambert PC, Burton PR, et al. Recurrent cough: natural history and significance in infancy and early childhood. Pediatr Pulmonol 1998;26:256-61.

7 Pattemore PK, Lampe FC, Smith S, et al. Asthma survey items as predictors of respiratory problems in children 2 yrs later: a longitudinal study. Eur Respir J 1999;14:650-8.

8 de Jongste JC, Shields MD. Cough - 2: Chronic cough in children. Thorax 2003;58:998-1003.

9 Schroeder K, Fahey T. Should we advise parents to administer over the counter cough medicines for acute cough? Systematic review of randomised controlled trials. Arch Dis Child 2002;86:170-5.

10 Davies MJ, Fuller P, Picciotto A, et al. Persisten nocturnal cough: randomised controlled trial of high dose inhaled corticosteroid. Arch Dis Child 1999;81:38-44.

11 Li AM, Lex C, Zacharasiewicz A, et al. Cough frequency in children with stable asthma: correlation with lung function, exhaled nitric oxide, and sputum eosinophil count. Thorax 2003; $58: 974-8$

12 Chang AB, Phelan PD, Robertson CF. Cough receptor sensitivity in children with acute and nonacute asthma. Thorax 1997;52:770-4.

13 Bousquet J, Chanez P, Lacoste JY, et al. Eosinophilic inflammation in asthma. NEngl J Med 1990;323:1033-9.

14 Douwes J, Gibson P, Pekkanen J, et al. Noneosinophilic asthma: importance and possible mechanisms. Thorax 2002;57:643-8.

15 Jatakanon A, Uasuf C, Maziak W, et al. Neutrophilic inflammation in severe persistent asthma. Am J Respir Crit Care Med 1999; 160:1532-9.

16 Ordonez CL, Shaughnessy TE, Matthay MA, et al. Increased neutrophil numbers and IL-8 levels in airway secretions in acute severe asthma: clinical and biologic significance. Am J Respir Crit Care Med 2000;161:1185-90.

17 Fahy JV, Kim KW, Liu J, et al. Prominent neutrophilic inflammation in sputum from subjects with asthma exacerbation. J Allergy Clin Immunol 1995; 95:843-52.

18 Sur S, Crotty TB, Kephart GM, et al. Sudden-onset fatal asthma. A distinct entity with few eosinophils and relatively more neutrophils in the airway submucosa? Am Rev Respir Dis 1993; 148:713-9.

19 Anees W, Huggins V, Pavord ID, et al. Occupational asthma due to low molecular weight agents: eosinophilic and non-eosinophilic variants. Thorax 2002;57:231-6.

20 Martin RJ, Cicutto LC, Smith HR, et al. Airways inflammation in nocturnal asthma. Am Rev Respir Dis 1991;143:351-7. 
21 Krawiec ME, Westcott JY, Chu HW, et al. Persistent wheezing in very young children is associated with lower respiratory inflammation. Am J Respir Crit Care Med 2001;163:1338-43.

22 Marguet C, Jouen-Boedes F, Dean TP, et al. Bronchoalveolar cell profiles in children with asthma, infantile wheeze, chronic cough, or cystic fibrosis. Am J Respir Crit Care Med 1999; 159:1533-40.

23 Najafi N, Demanet C, Dab I, et al. Differentia cytology of bronchoalveolar lavage fluid in asthmatic children. Pediatr Pulmonol 2003;35:302-8.

24 Stevenson EC, Turner G, Heaney LG, et al. Bronchoalveolar lavage findings suggest two different forms of childhood asthma. Clin Exp Allergy 1997;27:1027-35

25 Ennis M, Turner G, Schock BC, et al. Inflammatory mediators in bronchoalveolar lavage samples from children with and withou asthma. Clin Exp Allergy 1999;29:362-6.

26 Le Bourgeois M, Goncalves M, Le Clainche L, et al. Bronchoalveolar cells in children $<3$ years old with severe recurrent wheezing. Chest 2002; 122:791-7.

27 Cai Y, Carty K, Henry RL, et al. Persistence of sputum eosinophilia in children with controlled asthma when compared with healthy children. Eur Respir J 1998;1 1:848-53.

28 Azevedo I, de Blic J, Dumarey $\mathrm{CH}$, et al. Increased spontaneous release of tumour necrosis factor-alpha by alveolar macrophages from wheezy infants. Eur Respir J 1997; 10:1767-73.

29 Gibson PG, Norzila MZ, Fakes K, et al. Pattern of airway inflammation and its determinants in children with acute severe asthma. Pediatr Pulmonol 1999;28:261-70.

30 Norzila MZ, Fakes K, Henry RL, et al. Interleukin8 secretion and neutrophil recruitment accompanies induced sputum eosinophi activation in children with acute asthma. Am J Respir Crit Care Med 2000;161:769-74.

31 Cox G. Glucocorticoid treatment inhibits apoptosis in human neutrophils. Separation of survival and activation outcomes. J Immunol 1995; 154:4719-25.

32 Meagher LC, Cousin JM, Seckl JR, et al Opposing effects of glucocorticoids on the rate of apoptosis in neutrophilic and eosinophilic granulocytes. J Immunol 1996;156:4422-8.

33 O'Donnell RA, Frew AJ. Is there more than one inflammatory phenotype in asthma? Thorax 2002;57:566-8.

34 Stick SM, Holt PG. The airway epithelium as immune modulator: the LARC ascending. Am J Respir Cell Mol Biol 2003;28:641-4.

35 Knight DA, Holgate ST. The airway epithelium: structural and functional properties in health and disease. Respirology 2003;8:432-46.

36 Chung KF, Barnes PJ. Cytokines in asthma Thorax 1999;54:825-57.

37 Kamath AV, Pavord ID, Ruparelia PR, et al. Is the neutrophil the key effector cell in severe asthma? Thorax 2005;60:529-30.

38 Mikami M, Llewellyn-Jones CG, Bayley D, et al. The chemotactic activity of sputum from patients with bronchiectasis. Am J Respir Crit Care Med 1998; 157:723-8.

39 Colotta F, Re F, Polentarutti N, et al. Modulation of granulocyte survival and programmed cell death by cytokines and bacterial products. Blood 1992;80:2012-20.

40 Lee A, Whyte MK, Haslett C. Inhibition of apoptosis and prolongation of neutrophil functional longevity by inflammatory mediators. $J$ Leukoc Biol 1993;54:283-8.

41 Matute-Bello G, Liles WC, Radella F, et al. Neutrophil apoptosis in the acute respiratory distress syndrome. Am J Respir Crit Care Med 1997; 156:1969-77.

42 Kotecha S, Mildner RJ, Prince LR, et al. The role of neutrophil apoptosis in the resolution of acute lung injury in newborn infants. Thorax 2003:58:961-7.

43 Martin TR. Neutrophils and lung injury: getting it right. J Clin Invest 2002; 1 10:1603-5.

44 Borregaard N, Cowland JB. Granules of the human neutrophilic polymorphonuclear leukocyte. Blood 1997;89:3503-21.

45 Hiemstra PS, van Wetering S, Stolk J. Neutrophil serine proteinases and defensins in chronic obstructive pulmonary disease: effects on pulmonary epithelium. Eur Respir J 1998; 12:1200-8.

46 Liu H, Lazarus SC, Caughey GH, et al. Neutrophil elastase and elastase-rich cystic fibrosis sputum degranulate human eosinophils in vitro. Am J Physiol 1999;276:L28-34.

47 Nadel JA, Takeyama K, Agusti C. Role of neutrophil elastase in hypersecretion in asthma. Eur Respir J 1999;13:190-6.

48 Persson CG. Role of plasma exudation in asthmatic airways. Lancet 1986:2:1126-9.

49 Anticevich SZ, Hughes JM, Black JL, et al. Induction of hyperresponsiveness in human airway tissue by neutrophils: mechanism of action. Clin Exp Allergy 1996;26:549-56.

\section{Occupational asthma}

\section{Abramson, M R Sim}

\section{Early cessation of exposure is important}

$\mathrm{O}$ ccupational asthma is the commonest form of occupational ung disease in many Western countries, ${ }^{1-4}$ having overtaken the pneumoconioses in these countries owing to improved control of exposure to silica, asbestos, and coal dust. The reported incidence ranges from 13 per million workers in South Africa ${ }^{5}$ to 174 per million workers in Finland. ${ }^{6}$ It has been estimated that occupational factors may be responsible for $15 \%$ of all cases of adult onset asthma. ${ }^{7}$ The financial costs of occupational asthma in the US alone were estimated at between \$1.1 and $\$ 2.1$ billion in $1996 .{ }^{8}$

Although occupational causes are relatively uncommon, they are important because, unlike most other forms of asthma, occupational asthma is eminently preventable. However, one of the challenges in prevention is the fact that there are several hundred known causes arising from many occupations in most major industries. ${ }^{34}$ This is one of the reasons why prevention strategies are often unsuccessful. ${ }^{9}$ To be successful, clinicians and occupational health practitioners need to be actively involved with the primary, secondary and tertiary prevention of occupational asthma.

Primary prevention is about the maintenance of safe working conditions and avoiding exposure to known sensitisers and irritants. A good example with which many readers would be familiar comes from the healthcare industry. A recent systematic review found evidence that substituting powdered latex gloves with low protein powder free gloves or latex free gloves greatly reduced latex aeroallergen, sensitisation, and asthma in healthcare workers. ${ }^{10}$ This evidence was rated as SIGN level 2+, indicating that it came from well conducted observational studies with a low risk of bias or confounding and a moderate probability that the relationship was causal.

Secondary prevention of occupational asthma involves screening of workforces at risk. Workers known to be exposed to asthmagenic agents should undergo regular health surveillance. Cases of occupational asthma need to be identified early because continuing exposure results in worse symptoms, a faster decline in lung function, and a poorer prognosis. ${ }^{3}$ Clinicians usually only become involved with diagnosis, management and rehabilitation-that is, tertiary prevention of occupational asthma. Respiratory symptoms from unrecognised or undertreated asthma cause work related respiratory disability among young adults in many countries. ${ }^{11}$ While a key principle of management, removal from exposure often entails loss of job with the consequent socioeconomic disadvantages.

In this issue of Thorax Anees and colleagues report a study of the decline in forced expiratory volume in 1 second $\left(\mathrm{FEV}_{1}\right)$ in a series of patients with occupational asthma in Birmingham. ${ }^{12}$ The authors found that $\mathrm{FEV}_{1}$ was declining by $101 \mathrm{ml} /$ year before removal from occupational exposure. Following removal from exposure, $\mathrm{FEV}_{1}$ actually improved by $12.3 \mathrm{ml}$ and subsequently declined by only $27 \mathrm{ml} /$ year, a rate similar to what would be expected in a working age population. The authors admitted the likelihood of selection bias and the fact that they could not always be certain precisely when removal from exposure had occurred. The lack of an effect of current smoking on decline in $\mathrm{FEV}_{1}$ was surprising and might be due to a "healthy smoker" effect. 